\title{
Atmospheric Mercury Monitoring, Analysis, and Chemistry: New Insights and Progress toward Minamata Convention Goals
}

\author{
James V. Cizdziel
}

check for updates

Citation: Cizdziel, J.V Atmospheric Mercury Monitoring, Analysis, and Chemistry: New Insights and Progress toward Minamata Convention Goals. Atmosphere 2021, 12, 166. https://doi.org/ $10.3390 /$ atmos 12020166

Received: 11 January 2021

Accepted: 26 January 2021

Published: 28 January 202

Publisher's Note: MDPI stays neutral with regard to jurisdictional claims in published maps and institutional affiliations.

Copyright: (C) 2021 by the author. Licensee MDPI, Basel, Switzerland. This article is an open access article distributed under the terms and conditions of the Creative Commons Attribution (CC BY) license (https:// creativecommons.org/licenses/by/ $4.0 /)$.
Department of Chemistry and Biochemistry, University of Mississippi, University, MS 38677, USA; cizdziel@olemiss.edu

Mercury is a persistent and toxic global contaminant that is transported through the atmosphere, deposits to terrestrial and aquatic ecosystems, and concentrates up the food chain reaching levels that can harm both humans and wildlife [1]. In this Special Issue on atmospheric mercury $(\mathrm{Hg})$, seven original research articles and a review paper report the latest findings describing the distribution, deposition, and measurement of this airborne pollutant as well as the human and environmental impacts of artisanal mining of $\mathrm{Hg}$ and gold. The papers span a wide range of investigations including the determination of Hg deposition in northwest USA [2], southeast Europe [3], and Chongming Island, near Shanghai, China [4]; the development and use of iodinated activated carbon for traceable determination of airborne $\mathrm{Hg}$ [5]; new measurements of atmospheric $\mathrm{Hg}$ along the northern Gulf of Mexico using passive air sampling [6]; the impacts of artisanal gold mining and associated $\mathrm{Hg}$ trade in south and central America [7,8]; and a timely review on reactive $\mathrm{Hg}$ in ambient air [9]. This editorial provides highlights of these interesting papers and presents them in the broader context of modern atmospheric $\mathrm{Hg}$ research and the Minamata Convention on Mercury, a global treaty now signed by 127 parties and designed to protect human health and the environment from anthropogenic emissions of $\mathrm{Hg}$.

Advances in measuring atmospheric $\mathrm{Hg}$ have improved our understanding of its sources, transport, transformations, fluxes, and fate. Airborne $\mathrm{Hg}$ is generally categorized as gaseous elemental mercury (GEM) and reactive mercury (RM), with the latter representing gaseous oxidized mercury (GOM) and particle-bound mercury (PBM). Accurately measuring RM as a whole is challenging, let alone individual $\mathrm{Hg}$ compounds. Gustin et al. [9] provide a review focusing on the fascinating history of efforts to quantify and characterize RM, along with the current state of such measurements and knowledge. Methods for measuring RM are changing as concerns over artifacts or repeatability emerge or as knowledge of RM improves. Early work using mist chambers [10], filters and membranes [11], and denuders [12] naturally resulted in inter-comparison studies, especially after an automated system became commercially available from Tekran ${ }^{\circledR}$ Instruments Corporation that improved temporal resolution. The Tekran speciation system was an important step forward because as $\mathrm{Hg}$ sources and oxidant chemistry of the air vary, so too do levels of RM. The Tekran, as it is known, became standard, and the system was employed by researchers worldwide. More recently, it was demonstrated that the $\mathrm{KCl}$ denuder used in the Tekran is not adequate for measuring RM concentration [9], and so the development of new methods continues. Among them are the Reactive Mercury Active System (RMAS) and the ever-promising mass spectrometry. Moving forward, the review authors strongly advocate for the field calibration of oxidized $\mathrm{Hg}$ measurements. The review concludes with useful sections on "what we have learned" and "work needed."

Continuing on the important theme of attaining accurate and reliable measurements, Zivkovic and colleagues [5] investigated spiking of a standard reference material (NIST 3133) directly onto iodinated activated carbon (AC) traps for accurate and traceable calibration determination of ambient $\mathrm{Hg}^{0}$. Measurements were made by atomic absorption spectrometry after sample combustion. There were identical responses between $\mathrm{Hg}$ loaded 
directly and $\mathrm{Hg}$ loaded by purging from the NIST solution after reduction with $\mathrm{SnCl}_{2}$ across a wide concentration range (10-2000 ng). Further proof-of-concept studies on real atmospheric samples, where accuracy was assessed by a different reference material, showed that the approach is, indeed, effective for measuring atmospheric Hg. The authors include details for preparation and optimization of the quantitative analysis setup. They also deconvoluted peaks of fractionation thermograms to identify iodide of Millon's base $\left(\mathrm{HgO} \cdot \mathrm{Hg}\left(\mathrm{NH}_{3}\right)_{2} \mathrm{I}_{2}\right)$ as the likely final $\mathrm{Hg}$ complexing agent.

In another study employing AC for GEM measurements, Jeon et al. [6] deployed MerPAS ${ }^{\circledR}$ passive air samplers (PASs) containing sulfur impregnated AC along the northern Gulf of Mexico. The region has high $\mathrm{Hg}$ wet deposition rates and high levels of $\mathrm{Hg}$ in seafood compared to other coastlines in the USA. Unlike the Tekran speciation system discussed earlier, these PASs are relatively inexpensive and require no external power. Thus, they are typically deployed to increase area coverage and improve spatial resolution, albeit with poorer temporal resolution since they often need to be placed outdoors for several weeks to capture enough $\mathrm{Hg}$ for measurement. The PASs discriminate landscape and seasonal effects if given sufficient collection time, adequate analytical precision, and low blank levels [13]. Along the Gulf Coast, it was found that concentrations varied depending on proximity to sources and site characteristics, with a coastal marsh having the lowest GEM levels possibly due to uptake by vegetation. The PASs gave slightly lower concentrations compared to an active sampling system at Grand Bay, but generally showed similar seasonal patterns. Overall, the work demonstrates that PASs can provide insight into GEM levels and the factors affecting them along coastal regions.

As noted, three of the papers focused on $\mathrm{Hg}$ deposition. In Washington, USA, Beutel and colleagues [2] quantified both wet and dry $\mathrm{Hg}$ deposition at rural and suburban sites using a direct measurement approach with simple, low-cost equipment. The authors used an aerodynamic "wet sampler" for assessing dry deposition. GOM, PBM, and some GEM were collected in a thin layer of a recirculating acidic aqueous solution placed on a Teflon plate. The setup was operated for several days before the solution was collected, preserved, and analyzed for total-Hg. Wet deposition sampling was more standard. The rate was calculated as mass accumulation divided by the area of the collecting funnel and duration of the sampling event. The authors concluded that direct measurement approaches are useful in assessing temporal and spatial patterns of $\mathrm{Hg}$ deposition, and for comparing results to other approaches and estimates from numerical air quality models. They also show that agricultural burning in rural areas can lead to elevated levels of dry deposition and that short-term rain events account for $\sim 20 \%$ of $\mathrm{Hg}$ deposition during the dry season.

Meanwhile, Tang et al. [4] examined Hg wet deposition on Chongming Island, China, from 2014-2018 to understand $\mathrm{Hg}$ wet deposition characteristics over multiple years. Notably, this is a period that saw the implementation of the Minamata Convention and anthropogenic $\mathrm{Hg}$ emission controls that allowed evaluation of the effectiveness of those controls. Volume-weighted mean $\mathrm{Hg}$ concentrations decreased during the study period, which was explained by decreasing atmospheric $\mathrm{Hg}$ levels and anthropogenic emission reductions. The authors also examined the impact of meteorological variations and showed that large-scale meteorological circulation events (e.g., monsoons) significantly impact $\mathrm{Hg}$ wet deposition. Thus, they recommend using long-term $\mathrm{Hg}$ wet deposition flux values in future $\mathrm{Hg}$ assessment programs to evaluate the impact of anthropogenic emissions reductions and inter-annual meteorological conditions.

Biomonitoring is yet another approach to measure $\mathrm{Hg}$ deposition, but one that requires no sampling equipment, other than that needed to retrieve the biota. Here, Stafilov et al. [3] used two species of moss blanketing North Macedonia to examine spatial and temporal patterns of $\mathrm{Hg}$ deposition within the eastern European region. The authors determined $\mathrm{Hg}$ in the samples collected as far back as 2002. Analysis of the median values showed an increase from 2002 to 2010 and a slight reduction from 2010 to 2015. Mercury distribution maps showed that sites with increased concentrations of $\mathrm{Hg}$ in moss were likely impacted by anthropogenic pollution; sites include thermoelectric power plants and a former chlor- 
alkali plant. It was concluded that $\mathrm{Hg}$ air pollution in the region is highest in industrialized areas. The authors rightfully note that such work is important for modeling $\mathrm{Hg}$ pollution and monitoring future trends in deposition, in order to assess and preserve ecosystem health. This is also a nice segue to the last two papers to be highlighted.

A good way to conclude this editorial are the contributions from Brown et al. [7] and Marshall et al. [8] on the environmental and health impacts of mining, bringing us back to the Minamata Convention on Mercury. It is undeniable that artisanal and small-scale gold mining (ASGM) employing $\mathrm{Hg}$ has major impacts on $\mathrm{Hg}$ pollution. Gold amalgamation with $\mathrm{Hg}^{0}$, which incidentally is used in many of our instruments to concentrate and isolate $\mathrm{Hg}$ prior to spectroscopic analysis, is still commonly used in the developing world to separate gold from unwanted minerals, despite the means to do so without $\mathrm{Hg}$ [14]. I applaud the work of Brown and colleagues involving a training program to monitor elemental $\mathrm{Hg}$ emissions originating from gold shops in Guyana, South America. The effort included both locals and undergraduate student researchers from the USA, offering a meaningful educational experience for both. Several gold shops had measurements exceeding $100,000 \mathrm{ng} / \mathrm{m}^{3}$, the guideline for occupational exposure limits in the USA. The authors note that while their work identified this significant source of $\mathrm{Hg}^{0}$ emissions, it did not provide insight into the fate of this $\mathrm{Hg}$. They also suggest that future mapping incorporating data from passive air samplers, like those discussed earlier, may add to our understanding of the fate of $\mathrm{Hg}^{0}$ emitted from gold shops. Finally, they astutely point out that ASGM continues to be a global challenge faced by not only Guyana and other nations engaged in ASGM activities, but also all signatory nations of the Minamata Convention.

Last, but not least, Marshall et al. [8] reported on $\mathrm{Hg}$ challenges faced by Mexico involving regulatory, trade, and environmental impacts. While official $\mathrm{Hg}$ exports have declined, primary artisanal $\mathrm{Hg}$ mining in Mexico continues to proliferate, as does its associated problems. The authors include a brief history of $\mathrm{Hg}$ mining in Mexico, a description of the key stages of the mining process, and an analysis of $\mathrm{Hg}$ supply and trade in several countries of South America that have large ASGM sectors, leading to the examination of the regulatory control suggested by the Minamata Convention directives. They also provide atmospheric $\mathrm{Hg}$ concentrations measured at mine sites. The authors conclude that as the gold price remains high and artisanal gold mining using $\mathrm{Hg}$ amalgamation proliferates around the world, the demand for $\mathrm{Hg}$ from countries like Mexico and Indonesia will continue unabated, even with implementation of international agreements like the Minamata Convention. Finally, they discuss the economic alternatives that could be promoted in the region to substitute the destructive practices associated with primary $\mathrm{Hg}$ mining. I personally appreciate the final section on recommendations and future steps, which is a must read for stakeholders.

In summary, this group of articles provide a valuable update on atmospheric $\mathrm{Hg}$ research, showing not just how far we have come as a research community, but how far we must still go. The research stems from around the world, exemplifying that $\mathrm{Hg}$ is a global pollutant that affects us all. I thank the authors for their valuable contributions and hope this issue sparks some thought, collaboration, or simply serves as a resource to move us forward in a rapidly changing world and climate.

Funding: This research received no external funding.

Institutional Review Board Statement: Not applicable.

Informed Consent Statement: Not applicable.

Data Availability Statement: Not applicable.

Conflicts of Interest: The authors declare no conflict of interest. 


\section{References}

1. Driscoll, C.T.; Mason, R.P.; Chan, H.M.; Jacob, D.J.; Pirrone, N. Mercury as a Global Pollutant: Sources, Pathways, and Effects. Environ. Sci. Technol. 2013, 47, 4967-4983. [CrossRef] [PubMed]

2. Beutel, M.W.; DeSilva, L.; Amegbletor, L. Direct Measurement of Mercury Deposition at Rural and Suburban Sites in Washington State, USA. Atmosphere 2021, 12, 35. [CrossRef]

3. Stafilov, T.; Barandovski, L.; Šajn, R.; Bačeva Andonovska, K. Atmospheric Mercury Deposition in Macedonia from 2002 to 2015 Determined Using the Moss Biomonitoring Technique. Atmosphere 2020, 11, 1379. [CrossRef]

4. Tang, Y.; Wu, Q.; Gao, W.; Wang, S.; Li, Z.; Liu, K.; Han, D. Impacts of Anthropogenic Emissions and Meteorological Variation on Hg Wet Deposition in Chongming, China. Atmosphere 2020, 11, 1301. [CrossRef]

5. Živković, I.; Berisha, S.; Kotnik, J.; Jagodic, M.; Horvat, M. Traceable Determination of Atmospheric Mercury Using Iodinated Activated Carbon Traps. Atmosphere 2020, 11, 780. [CrossRef]

6. Jeon, B.; Cizdziel, J.V.; Brewer, J.S.; Luke, W.T.; Cohen, M.D.; Ren, X.; Kelley, P. Gaseous Elemental Mercury Concentrations along the Northern Gulf of Mexico Using Passive Air Sampling, with a Comparison to Active Sampling. Atmosphere 2020, 11, 1034. [CrossRef]

7. Brown, S.T.; Bandoo, L.L.; Agard, S.S.; Thom, S.T.; Gilhuys, T.E.; Mudireddy, G.K.; Eechampati, A.V.; Hasan, K.M.; Loving, D.C.; Seney, C.S.; et al. A Collaborative Training Program to Assess Mercury Pollution from Gold Shops in Guyana's Artisanal and Small-Scale Gold Mining Sector. Atmosphere 2020, 11, 719. [CrossRef]

8. Marshall, B.G.; Camacho, A.A.; Jimenez, G.; Veiga, M.M. Mercury Challenges in Mexico: Regulatory, Trade and Environmental Impacts. Atmosphere 2020, 12, 57. [CrossRef]

9. Gustin, M.S.; Dunham-Cheatham, S.M.; Huang, J.; Lindberg, S.; Lyman, S.N. Development of an Understanding of Reactive Mercury in Ambient Air: A Review. Atmosphere 2021, 12, 73. [CrossRef]

10. Stratton, W.J.; Lindberg, S.E. Use of a refluxing mist chamber for measurement of gas-phase mercury(ii) species in the atmosphere. Water Air Soil Pollut. 1995, 80, 1269-1278. [CrossRef]

11. Ebinghaus, R.; Jennings, S.G.; Schroeder, W.H.; Berg, T.; Donaghy, T.; Guentzel, J.; Kenny, C.; Kock, H.H.; Kvietkus, K.; Landing, W.; et al. International field intercomparison measurements of atmospheric mercury species at Mace Head, Ireland. Atmos. Environ. 1999, 33, 3063-3073. [CrossRef]

12. Feng, X.B.; Sommar, J.; Gardfeldt, K.; Lindqvist, O. Improved determination of gaseous divalent mercury in ambient air using $\mathrm{KCl}$ coated denuders. Fresenius J. Anal. Chem. 2000, 366, 423-428. [CrossRef] [PubMed]

13. Jeon, B.; Cizdziel, J.V. Can the MerPAS Passive Air Sampler Discriminate Landscape, Seasonal, and Elevation Effects on Atmospheric Mercury? A Feasibility Study in Mississippi, USA. Atmosphere 2019, 10, 617. [CrossRef]

14. Drace, K.; Kiefer, A.M.; Veiga, M.M.; Williams, M.K.; Ascari, B.; Knapper, K.A.; Logan, K.M.; Breslin, V.M.; Skidmore, A.; Bolt, D.A.; et al. Mercury-free, small-scale artisanal gold mining in Mozambique: Utilization of magnets to isolate gold at clean tech mine. Atmosphere 2012, 32, 88-95. [CrossRef] 